International Journal of Engineering \& Technology, $7(2.33)(2018)$ 6-10
International Journal of Engineering \& Technology
WPC
Website: www.sciencepubco.com/index.php/IJET
Research paper

\title{
Parametric study on heat transfer characteristics of waste heat recovery heat exchanger for automotive exhaust thermoelectric generator
}

\author{
Ki. Hyun Kim ${ }^{1}$, Mahesh Suresh Patil ${ }^{2}$, Jae-Hyeong Seo ${ }^{3}$, Chan-Jung Kim ${ }^{4}$, Gee-Soo Lee ${ }^{4}$, Moo-Yeon Lee ${ }^{5}$ \\ ${ }^{1}$ Division of Mechanical Convergence Engineering, Silla University, Republic of Korea \\ ${ }^{2}$ Graduate School of Mechanical Engineering, Dong-A University Hadan 840, Saha-gu, Busan 604-714, Republic of Korea \\ ${ }^{3}$ Department of Mechanical Design Engineering, Pukyong National University, Republic of Korea, cjkim@pknu.ac.kr \\ ${ }^{4}$ Department of Smart Automotive Engineering, Youngsan University, Republic of Korea \\ ${ }^{5}$ Department of Mechanical Engineering, Dong-A University Hadan 840, Saha-gu, Busan 604-714, Republic of Korea \\ *Corresponding authorE-mail: khkim3@silla.ac.kr
}

\begin{abstract}
Background/Objectives: The parametric study on heat transfer characteristics of waste heat recovery heat exchanger was carried out by varying different geometry parameters to suggest optimum model for automotive exhaust thermoelectric generator.

Methods/Statistical analysis: The numerical analysis method was applied to compare the heat transfer characteristics of various heat exchanger models. For numerical analysis, various models were created using computer aided drawing considering different fin arrangements and guide plates. Commercial code ANSYS 17.0 was used to analyze the heat transfer and fluid flow behavior of various models. Mesh independency was conducted to enhance the accuracy of the results.

Findings: The thermal performance analysis of waste heat recovery heat exchanger was conducted considering pressure drop and heat flux at cooling side. As the fin spaces were increased, the heat flux at cooling side increased, but pressure drop also increased.

Improvements/Applications: The developed geometry can be further optimized considering other geometry parameters and efficient system could be developed for power generation using waste heat with heat recovery exchanger and the present study provides detailed numerical analysis considering pressure drop and heat flux.
\end{abstract}

Keywords: Guide Plate; Heat Exchanger; Numerical Study; Thermoelectric Generator; Waste Heat Recovery.

\section{Introduction}

Reduction of energy consumption of an automotive has widely gained attention during recent years. Some technologies have been intensively studied to improve the mileage of an automotive. Thermoelectric generation is one of the promising technologies for mileage improvement of an automotive. Thermoelectric generation is a technology to generate the electricity from the heat with high temperature based on Seebeck effect [1]. Only about $30 \%$ of the energy generated in internal combustion (IC) engine is utilized as mechanical energy for an automotive drive [2]. Therefore, thermoelectric generation is expected to provide a way to enhance the performance of IC engine-based vehicles by recovering waste heat into electricity. Heo et al. experimentally and numerically studied the heat transfer behavior of various inside shape components of plate-type heat exchanger and showed that brass as construction material could provide enhanced effectiveness for thermoelectric power generation using wasted heat [3]. Various geometrical parameters including dimensions of thermoelectric generator, number of thermoelectric modules, fin parameters of heat exchanger, thickness of heat exchanger play important role in designing the heat exchangers [4-5]. Astrain et al. showed heat transfer coefficient along with overall thermal resistance depends on geometrical parameters of the heat exchanger under consideration. They pointed out that as surface area available for heat ex- change increased, the thermal resistance got decreased [6] Flow parameters including mass flow rate at the exhaust of a vehicle and volumetric capacity of the exhaust gas influence the total power generation and efficiency of the TEG system [7-8]. Kumat et al. studied the thermal performance of helical double tube heat exchanger and found that performance was influenced by innercoil tube dimensions [9]. Kim et al. considered gap between surfaces of thermoelectric module and heat exchanger as a critical criterion for electricity generation efficiency [10]. Surface area available for heat transfer is an important parameter and could influence thermoelectric power generation in waste heat recovery [11]. Recently, Patil et al. suggested that for the same volume, segmented asymmetric thermoelectric element have higher conversion efficiency than segmented symmetric thermoelectric element [1]. Bang et al. analyzed the effect of variations in exhaust gas and ambient temperature on performance characteristics of thermoelectric generator [12].

However, precise and concise studies on the efficient structures such as guide plates and different fin configurations for recovery of wasted heat using heat exchanger to enhance the efficiency of the TEG devices have been not studied more intensively. Therefore, this paper focuses on analysis of the heat transfer performances of the waste heat recovery heat exchanger to apply to vehicles. The purpose of the present study is to numerically examine the thermal performance of the waste heat recovery heat ex- 
changer with various geometric parameters of inner heat sink and inner guide in diffusor for the waste heat recovery heat exchanger.

\section{Numerical method}

The details of numerical method are presented in this section. The relevant numerical analysis aspects for the current study including geometry details, meshing and mesh independency, physical assumptions, various initial and boundary conditions have been summarized. The mesh independency study was carried out to check the independency of results with the number of nodes and appropriate mesh was selected based on costing and mesh independency. The appropriate boundary conditions were selected based on the previous literature with relevancy to present study. The k- $\varepsilon$ model was considered as turbulence model for all cases considering simplicity and accuracy.

Figure 1 shows the schematic of the models used in the present study. Various models were considered based on the fin spaces and guide plates. The suggested model was developed to recover waste heat from an automobile exhaust for generating electricity using thermoelectric generators. The efficiency of thermoelectric generator is greatly dependent on the temperature distribution on hot side and cold side of generator. The hotter side of thermoelectric generator is attached to the waste heat recovery heat exchanger and colder side is generally attached to cooling channel. Therefore, the performance of waste heat recovery exchanger plays crucial part in the overall efficiency of the system. In this study, various geometry parameters were considered in order to examine the performance of the waste heat recovery heat exchanger.

(A) Fins Space

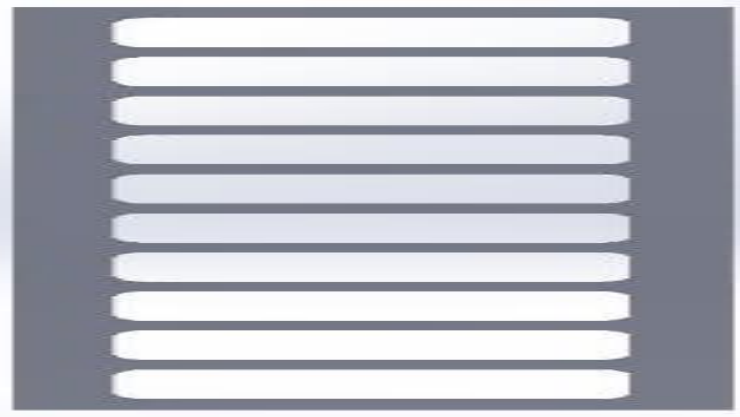

(B) Fins Space 12

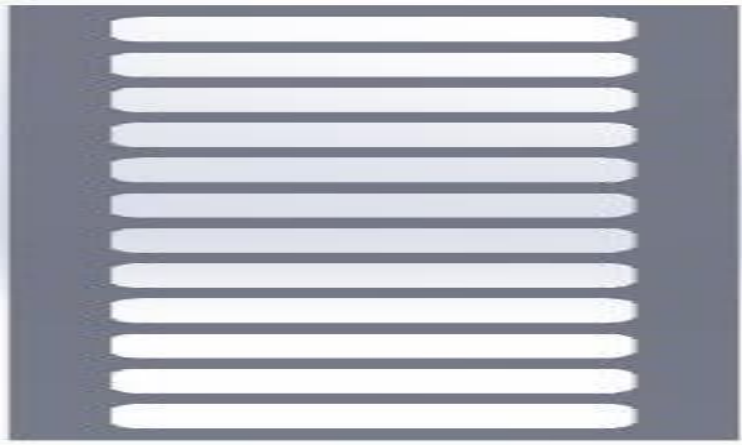

(C) Fins Space15

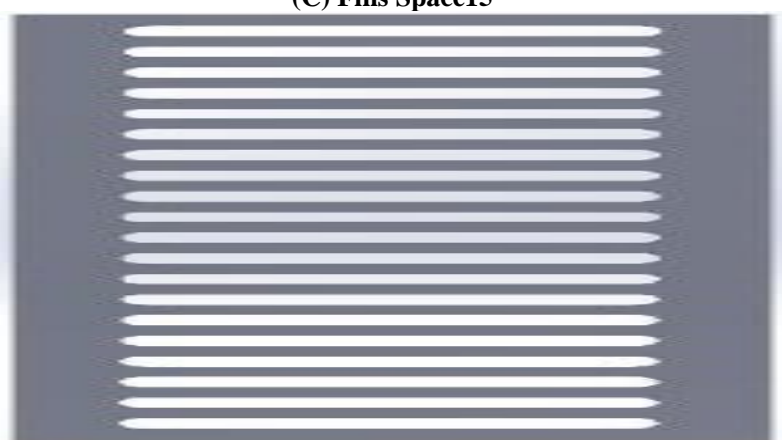

(D) Fins Space 20

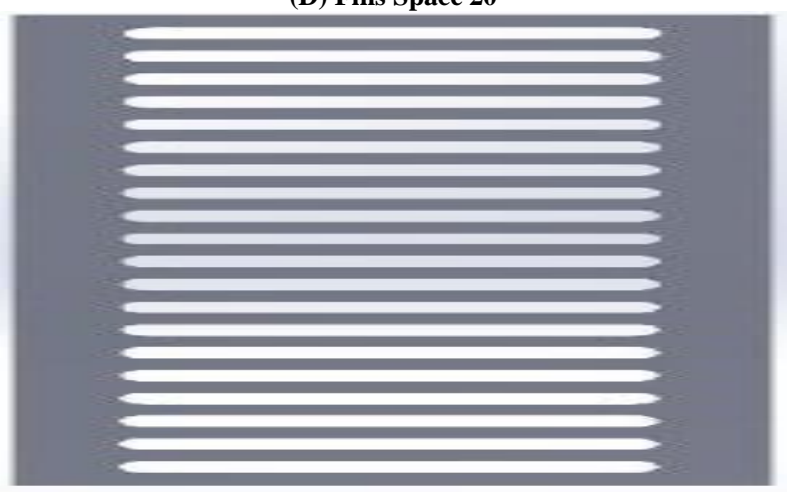

(E) With No Guide Plates.

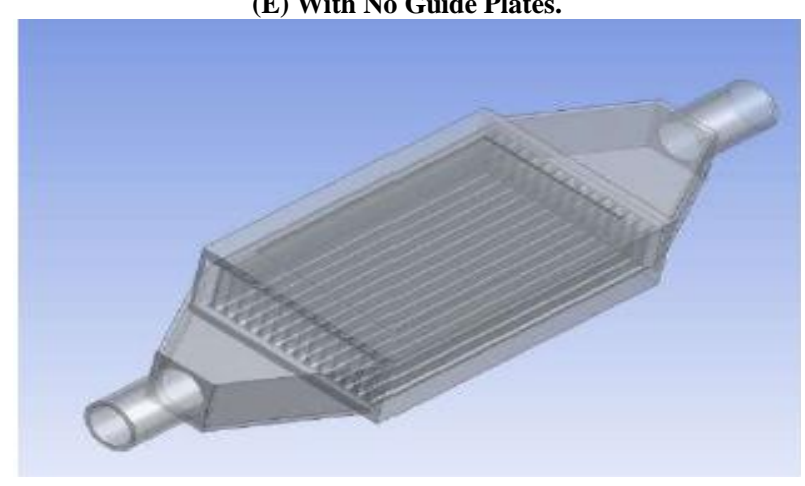

(F) With two Guide Plates.

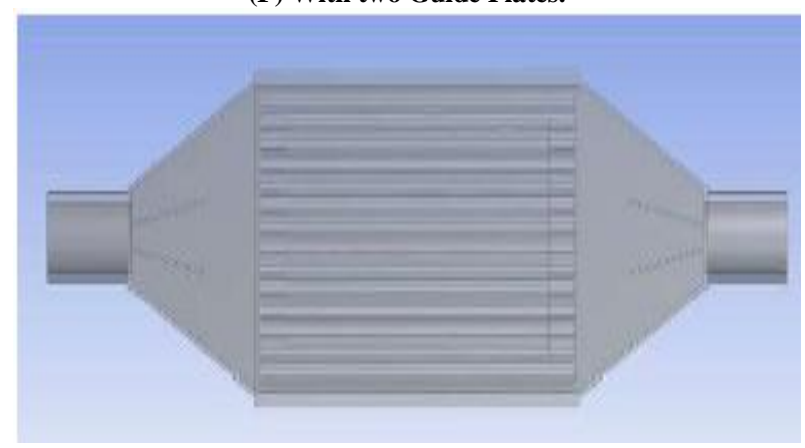

(G) With three Guide Plates.

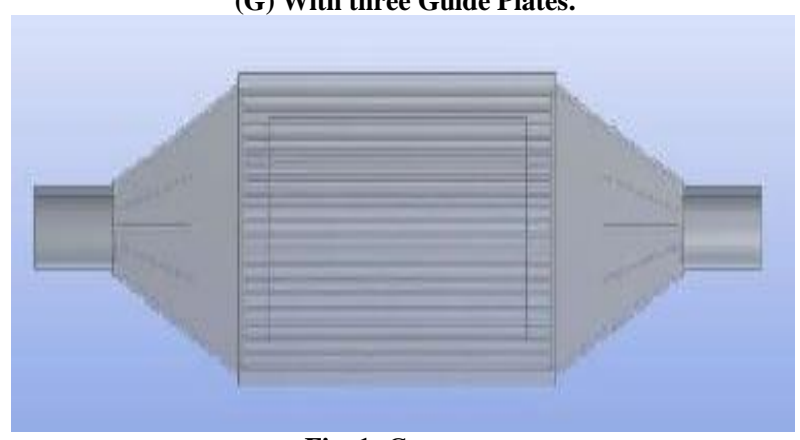

Fig. 1: Geometry.

Different meshing schemes were used to correctly predict the heat transfer and flow analysis of waste heat recovery heat exchanger. As the geometry under consideration had thin fins along with small gaps to flow the hot air, unstructured mesh type was used. Fine meshing was employed at area near walls and curvature to capture precise variation in the temperature, velocity and pressure. Total 2,131, 152 elements were generated with 667,328 nodes during meshing process. To enhance the accuracy of the analysis mesh independency test was carried out. The mesh independency test was performed considering pressure drop and heat flux at cooling side. Figure [2] shows that as the mesh numbers were increased from $2,131,152$ to $5,233,756$, the heat flux at cooling side and pressure drop were almost constant and varied within 
$0.5 \%$ after the mesh element numbers $2,131,152$. Thus, mesh independency test was conducted.

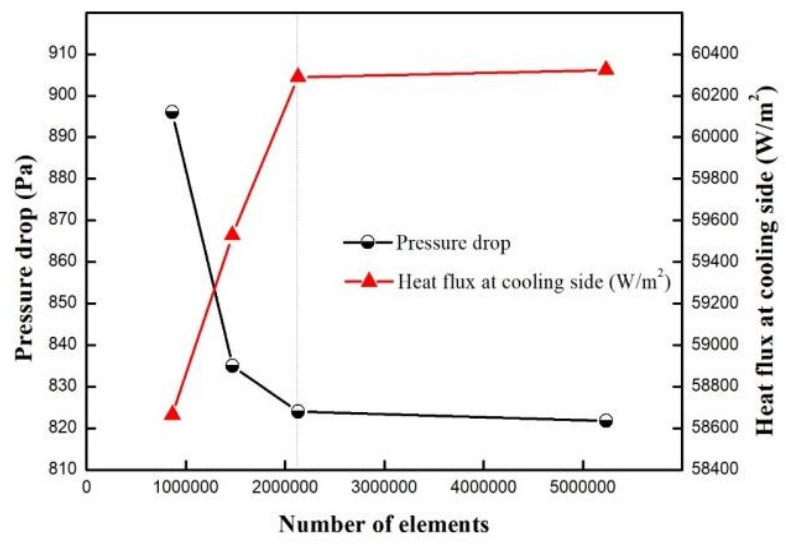

Fig. 2: Mesh Independence Test.

Table 1 shows details of the initial and boundary conditions employed in the current numerical analysis. Ansys 17.0 was used to analyze the temperature and flow distribution of the waste heat recovery heat exchanger. The inlet temperature of the exhaust hot gas was kept constant at $470{ }^{\circ} \mathrm{C}$ and heat transfer coefficient of cooling side was considered as $300 \mathrm{~W} / \mathrm{m}^{2}-\mathrm{K}$ to study the effect of various geometry parameters. Outlet boundary condition was considered with pressure outlet at atmospheric pressure for present simulation. The material of the construction was considered to be aluminum.

Table 1: Numerical Analysis Boundary Conditions

\begin{tabular}{ll}
\hline Parameter & Specification \\
\hline Working fluid & Hot air \\
Inlet hot gas temperature $\left({ }^{\circ} \mathrm{C}\right)$ & 470 \\
Inlet hot gas mass flow rate $(\mathrm{kg} / \mathrm{s})$ & 0.02828 \\
Cooling side heat transfer co-efficient $\left(\mathrm{Wm}^{-2} \mathrm{~K}^{-1}\right)$ & 300 \\
Wall slip & No-slip \\
Material of heat exchanger & Aluminum \\
Turbulence model & $\mathrm{k}-\varepsilon$ \\
\hline
\end{tabular}

\section{Results and discussion}

The performance of waste heat recovery heat exchanger was investigated considering various geometry parameters. The fin space and guide plate geometry were varied at constant hot air temperature of $470{ }^{\circ} \mathrm{C}$. The number of fin space of the heat exchanger was varied from 10 to 20 . Accordingly, the thickness of the fin was changed from $9 \mathrm{~mm}$ to $3 \mathrm{~mm}$. In order to enhance flow pattern and uniform temperature distribution for better heat transfer, effect of guide plates was investigated. The heat exchanger with guide plate of 2 and 3 were considered and results were compared to heat exchanger with no guide plate. This section summarizes the results of numerical study considering various parameters including temperature distribution, pressure drop variation of hot air and heat flux at cooling side.

Figure 3 shows the distribution of pressure drop and heat flux at cooling side with different number of fin spaces and with no guide plate. As the number of fin spaces increased the from 10 to 20 , the heat flux at cooling side increased by $38.5 \%$ due to increase in the surface area, but pressure drop increased $43.2 \%$ due to reduction in the cross-sectional flow area. The optimum point was discovered at the fin space number 16. The optimum point shows that the values of heat flux and pressure drop could be compared, and optimum fin space could be decided.

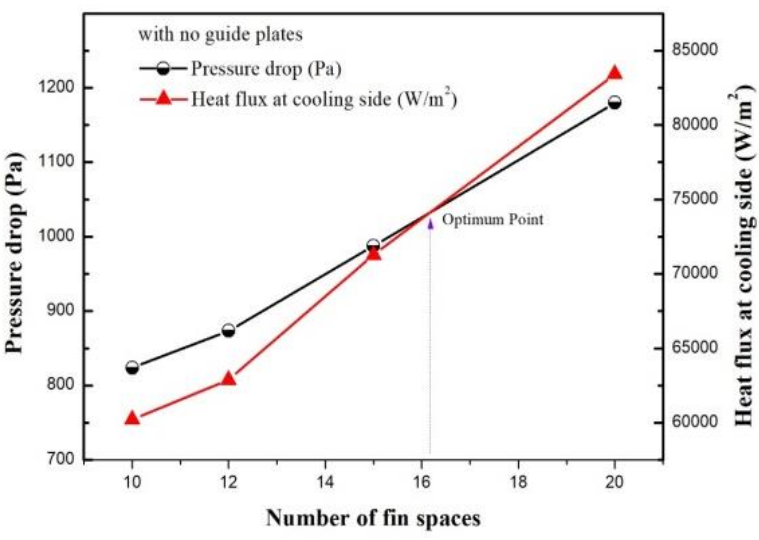

Fig. 3: Effect of Number of Fin Spaces on the Pressure Drop and Heat Flux at Cooling Side with No Guide Plate.

Figure 4 shows the distribution of pressure drop and heat flux at cooling side with different number of fin spaces and with [2] guide plates. As the number of fin spaces increased the from 10 to 20 , the heat flux at cooling side increased by $22.7 \%$ due to increase in the surface area, but pressure drop increased $12.2 \%$ due to reduction in the cross-sectional flow area. The optimum point was discovered at the fin space number 18 .

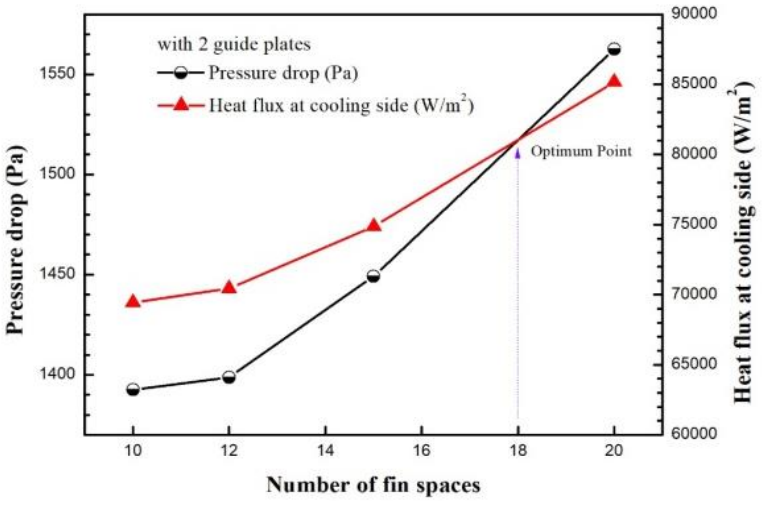

Fig. 4: Effect of Number of Fin Spaces on the Pressure Drop and Heat Flux at Cooling Side with [2] Guide Plates.

Figure 5 shows the distribution of pressure drop and heat flux at cooling side with different number of fin spaces and with 2 guide plates. As the number fin spaces increased the from 10 to 20 , the heat flux at cooling side increased by $22.7 \%$ due to increase in the surface area, but pressure drop increased $12.2 \%$ due to reduction in the cross-sectional flow area. The optimum point was discovered at the fin space number 19. The trend shows that as the guide plate number in increased from [0] to [3] the optimum point shifts more towards the higher fin space number.

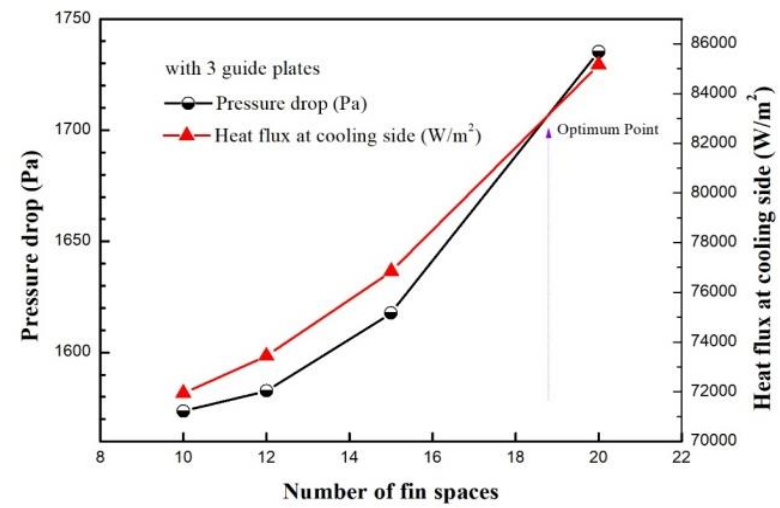

Fig. 5: Effect of Number of Fin Spaces on the Pressure Drop and Heat Flux at Cooling Side with [3] Guide Plates. 
Figure 6 shows the variation of average surface temperature of cooling side with different number of fin spaces and with guide plates. As the number of fin spaces increased the from 10 to 20 , the average surface temperature of cooling size increased indicating enhancement in the thermoelectric power generation. The results indicate that the more fin spaces and more guide plates could increase the power generation by thermoelectric generator as thermoelectric power generation greatly depends on hot side temperature. Figure [7] shows the temperature distribution of hot air for various geometry arrangements and it could be seen that more fin spaces and guide plate help in the uniform temperature distribution which could enhance the overall efficiency of the thermoelectric power generator.

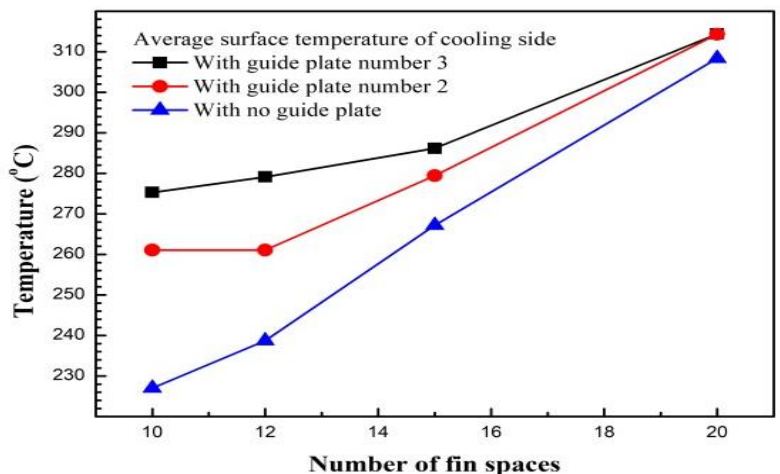

Fig. 6: Average Surface Temperature of Cooling Side.

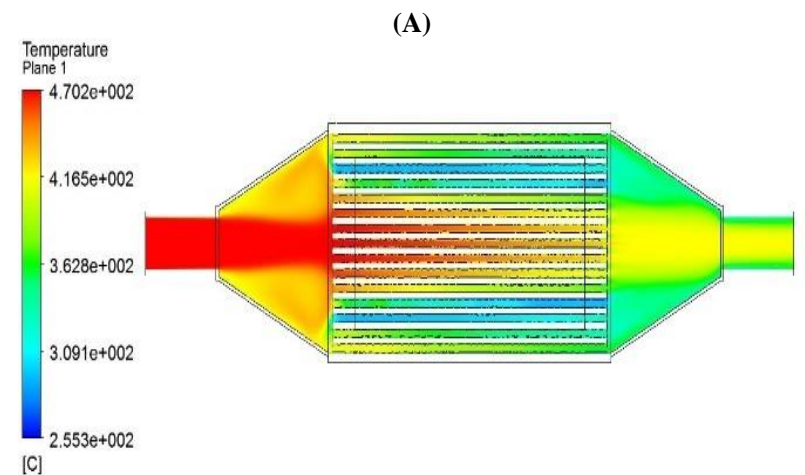

(B)

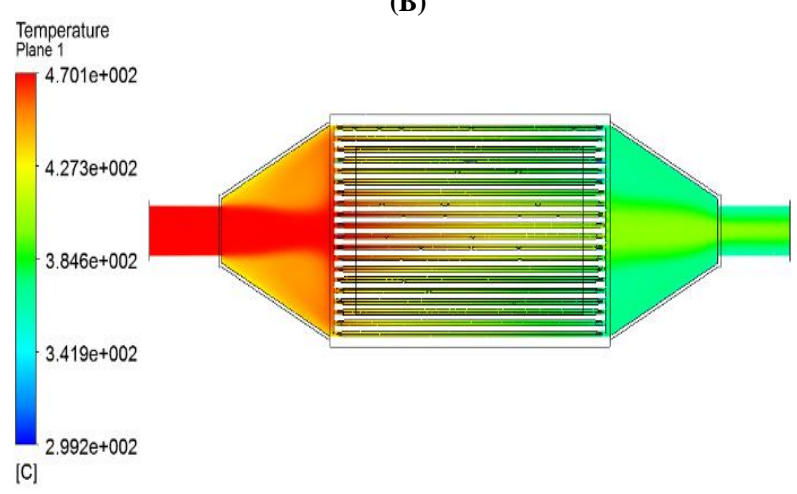

(C)

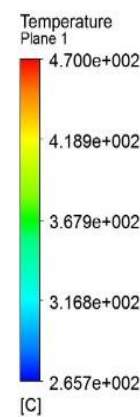

(D)

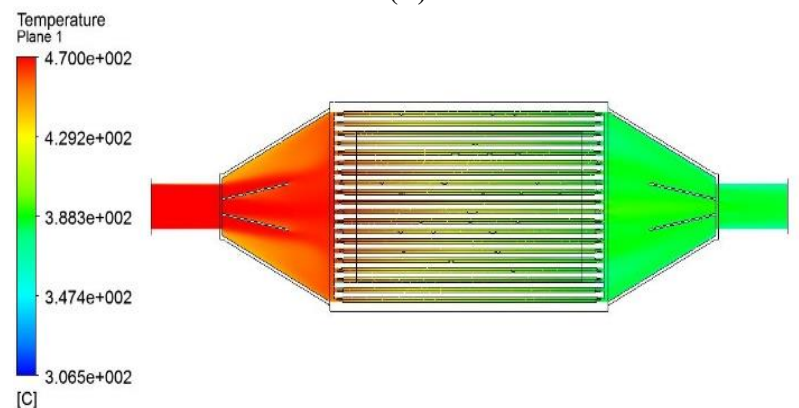

(E)

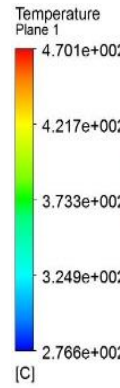

$[\mathrm{Cl}$

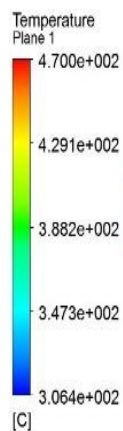

(F)

Fig. 7: Temperature Distribution (A) 15 Fin Spaces with No Guide Plate (B) 20 Fin Spaces with No Guide Plate (C) 15 Fin Spaces with 2 Guide Plates (D) 20 Fin Spaces with 2 Guide Plates (E) 15 Fin Spaces with 3 Guide Plates (F) 20 Fin Spaces with 3 Guide Plates.

\section{Conclusion}

The numerical analysis was conducted to investigate the thermal performance of waste heat recovery exchanger of thermoelectric generator. Pressure drop in the heat exchanger, temperature distribution of hot air and heat flux at cooling side were considered as performance parameters. The various geometry parameters including fin spaces and guiding plates were considered and its influence on pressure drop and heat flux were reported. The various geometry parameters including fin spaces and guiding plates were considered and its influence on pressure drop and heat flux were reported. In addition, the effect of guiding plate on thermal performance of heat exchanger were reported for flow pattern analysis and uniform temperature distribution. The study concludes that the guide plates could be effective tool for increasing the average surface temperature of hot side surface of thermoelectric generator at lower number of fin spaces. And, at higher number of fin spaces, guide plates are less effective.

\section{Acknowledgement}

This work was supported by the Dong-A University research fund. 


\section{References}

[1] Patil M.S, Seo J.H and Lee M.Y. Numerical study on geometric parameter effects of power generation performances for segmented thermoelectric generator. International Journal of Air-Conditioning and Refrigeration.2018, 26, 1850004

[2] Su C.Q, Wang W.S, Liu X, Deng Y.D. Simulation and experimental study on thermal optimization of the heat exchanger for automotive exhaust-based thermoelectric generators. Case Studies in Thermal Engineering. 2014 November 4, pp. 85-91.

[3] Heo H. S, Bae S. J, Hong S. M, Park S. U. Performance design of an exhaust super heater for waste heat recovery of construction equipment. KSAE 2016 Annual Spring Conference. 2016 May, pp. 154-165

[4] Martinez a Vian J.G, D, Rodriguez A, Berrio I. Optimization of the heat exchangers of a thermoelectric generation System. Journal of Electronic Materials.2010 September 39(9), pp. 1463-1468.

[5] Jeng T.M, Tzeng S.C, Yang B.J, Li Y.C. Design, manufacture and performance test of the thermoelectric generator system for waste heat recovery of engine exhaust. Inventions. 2016 January,1, 2; doi:10.3390/inventions 1010002

[6] Astrain D, Vian J.G, Martinez A, Rodriguez A. Study of the influence of heat exchangers' thermal resistances on a thermoelectric generation system. Energy.2010 February 35(2), pp. 602-610.

[7] Demir M.E, Dincer I. Development and heat transfer analysis of a new heat recovery system with thermoelectric generator. International Journal of Heat and Mass Transfer.2017 May, 8(B), pp. 2002-2010.

[8] Esarte J, Min G, Rowe D.M. Modelling heat exchangers for thermoelectric generators. Journal of Power Sources.2001 February 93(12), pp. 72-76.

[9] Kumar V, Saini S, Sharma M, Nigam K.D.P. Pressure drop and heat transfer study in tube-in-tube helical heat exchanger. Chemical Engineering Science.2006 July 61(13), pp. 4403-4416.

[10] Kim T.Y, Negash A, Cho G. Direct contact thermoelectric generator (DCTEG): A concept for removing the contact resistance between thermoelectric modules and heat source. Energy Conversion and Management.2017 June 142(15), pp. 20-27.

[11] Hsu C.T, Huang G.Y, Chu H.S, Yu B, Yao D.J. Experiments and simulations on low-temperature waste heat harvesting system by thermoelectric power generators. Applied Energy. 2011 April, 88(4) pp. 1291-1297.

[12] Bang Y.M, Seo J.H, Patil M.S, Ekanayake G, Doh Y.J, Lee G.S Yeom J.K, Lee M.Y. Study on performance characteristics of thermoelectric module with variations of exhaust gas and ambient temperatures. Korean Society of Mechanical Engineers (KSME) Busan chapter 2017, Busan, South Korea. 2017 May. 